\title{
Assessing factors associated with owner's individual decision to vaccinate their dogs against rabies: A house-to-house survey in Ouagadougou, Burkina Faso
}

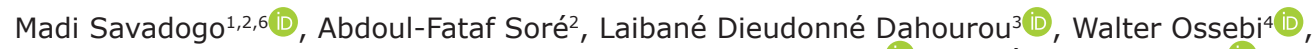 \\ Alima Hadjia Banyala Combari ${ }^{5}$, Rianatou Bada Alambedji ${ }^{(\mathbb{D}}$ and Zékiba Tarnagda ${ }^{1}$ (D)
}

1. Laboratoire National de Référence-Grippes (LNR-G), Unité des Maladies à potentiel Epidémique, Maladies Emergentes et Zoonoses, Département de Biologie Médicale et Santé Publique, Institut de Recherche en Sciences de la Santé (IRSS/CNRST), P.O. Box 7047, Ouagadougou, Burkina Faso; 2. Service de Microbiologie, Immunologie et Pathologies Infectieuses, Département de Santé Publique et Environnement, Ecole Inter-Etats des Sciences et Médecine Vétérinaires (EISMV), P.O. Box 5077, Dakar, Dakar, Senegal; 3. Department of Animal Husbandry, Environmental Sciences and Rural Development Institute, University of Dedougou (UDDG), P.O. Box 174, Dedougou, Burkina Faso; 4. Service d'Economie Rurale et Gestion, Département des Sciences Biologiques et Productions Animales, Ecole Inter-Etats des Sciences et Médecine Vétérinaires (EISMV), P.O. Box 5077, Dakar, Dakar, Sénégal; 5. Department of Animal Production, Environment and Agricultural Research Institute (INERA/CNRST), P.O. Box 910, Bobo Dioulasso, Burkina Faso; 6. Fundamental and Applied Research for Animals and Health (FARAH), Faculty of Veterinary Medicine, University of Liege, Quartier Vallée 2 avenue de Cureghem 10, Liege, Belgium.

Corresponding author: Madi Savadogo, e-mail: savadogo.madi@yahoo.fr Co-authors: AS: soreabdoulfataf@yahoo.fr, LDD: d_dahourou@yahoo.fr, WO: ossebi_3@yahoo.fr, AHBC: alima.combari@gmail.com,RBA: rianatoub@yahoo.fr, ZT: zekiba@hotmail.com

Received: 22-12-2020, Accepted: 17-03-2021, Published online: 27-04-2021

doi: www.doi.org/10.14202/vetworld.2021.1014-1019 How to cite this article: Savadogo M, Soré A, Dahourou LD, Ossebi W, Combari AHB, Bada Alambedji R, Tarnagda Z (2021) Assessing factors associated with owner's individual decision to vaccinate their dogs against rabies: A house-to-house survey in Ouagadougou, Burkina Faso, Veterinary World, 14(4): 1014-1019.

\begin{abstract}
Background and Aim: In rabies endemic area, dog vaccination is an effective way of controlling the disease in animals and humans if a minimum of $70 \%$ vaccination coverage is reached. This study aimed to identify dog demographics and household characteristics associated with dogs' vaccination against rabies in Ouagadougou, Burkina Faso.
\end{abstract}

Materials and Methods: A questionnaire was used to collect data from respondents with regard to their dogs' demographics and their household characteristics. Chi-square test and Fisher's exact test were performed to assess the association between explicative variables and the dogs' vaccination status.

Results: Overall, as per the findings of this study, it was determined that out of $424 \mathrm{dogs}, 57.8 \%$ were reportedly vaccinated. The vaccination status was significantly associated with most of the household variables (e.g., gender of the respondent, age, level of education, main means of transportation, participation in a vaccination campaign, knowledge on rabies, and knowledge on dog vaccination) and the dogs' variables (breed of dog, dog origin, purpose for keeping, confinement status, and perceived behavior) ( $\mathrm{p}<0.05)$. Moreover, only religion, type of housing, knowledge of rabies transmission modes, and dog sex were not significantly associated with vaccination status $(\mathrm{p}>0.05)$.

Conclusion: Our study generated informative data showing that animal health workers could develop effective rabies vaccination strategy planning by examining owned dog demographics and their husbandry practices in households.

Keywords: Burkina Faso, dog vaccination, household survey, owned dogs, rabies control.

\section{Introduction}

Rabies is considered a fatal disease transmitted to humans by bites mainly of domestic carnivores. It remains a major public health threat in Burkina Faso [1-4]. In the country's administrative capital, Ouagadougou, from 2003 to 2014, more than 60 persons have reportedly died from rabies; $40 \%$ of them were children under 15 years old [5]. The annual number of dog bites recorded in the

Copyright: Savadogo, et al. Open Access. This article is distributed under the terms of the Creative Commons Attribution 4.0 International License (http://creativecommons.org/licenses/ by/4.0/), which permits unrestricted use, distribution, and reproduction in any medium, provided you give appropriate credit to the original author(s) and the source, provide a link to the Creative Commons license, and indicate if changes were made. The Creative Commons Public Domain Dedication waiver (http:// creativecommons.org/publicdomain/zero/1.0/) applies to the data made available in this article, unless otherwise stated. country is one of the highest in the West Africa subregion [6-9].

To control and stop its threat, the country made rabies a notifiable disease [10]. Indeed, at the national level, regulations have prohibited dogs from roaming around and made the annual rabies vaccination compulsory for all dogs from 3 months of age and older. Most of the time, dog rabies vaccination should be possible in Ouagadougou because veterinary clinics and vaccines are more available compared to rural areas. Dog vaccination is provided by private animal health professionals at an estimated average cost of 15 euros [4]. In some areas, public animal health workers are also involved in dog vaccination against rabies. Unfortunately, large and free mass dog vaccination campaigns are not often organized in the country. This situation may significantly impede the geographical 
and financial accessibility of dog-owning households conducted in the same site by Savadogo et al. [4] showed a dog vaccination coverage of $33.5 \%$. However, many studies reported that mass vaccination campaigns achieving at least $70 \%$ of vaccination coverage are necessary in rabies-endemic areas to eradicate the disease in animals and humans [15-19].

In the study area, canine breeding practices and household socioeconomic factors that could influence the owner's decision to allow vaccination of their dogs have not been studied before. Therefore, this study aimed to identify dog demographics and household characteristics associated with rabies vaccination of dogs in Ouagadougou, Burkina Faso.

\section{Materials and Methods}

\section{Ethical approval and Informed consent}

This study obtained ethics approval from the Research Ethical Committee of the Universite Cheikh Anta Diop (Protocole-0322/2018/CER/UCAD). pants were informed about the background and purpose of the study, highlighting that their participation was voluntary, and that their answers would be kept confidential. Only participants who verbally agreed were interviewed.

\section{Study site and period}

Ouagadougou is the capital city of Burkina Faso, with an estimated population of 1.5 million people [10]. Located at the center of the country, the city is composed of 12 administrative boroughs and 55 administrative sectors. Recently, about 565,600 households were recorded in Ouagadougou [20]. This study was performed from August to November 2019 in 13 administrative sectors randomly selected from 12 administrative boroughs in Ouagadougou.

\section{Sampling and sampling method}

The target population included domestic carnivore-owning households. Using an estimated vaccination coverage of $33.5 \%$ obtained in domestic carnivores [4] and a standard error of 5\% with a $95 \%$ confidence level, the minimum required sample size was 342 households, but, in total, we were able to survey 384 households. The sample size was calculated using the formula of Thrusfield as follows:

$$
\mathrm{N}=\mathrm{Z}^{2} \mathrm{P}(1-\mathrm{P}) / \mathrm{M}^{2}
$$

$\mathrm{Z}$ value is 1.96 at the confidence level of $95 \%, \mathrm{P}$ is the estimated vaccination coverage percentage, and $\mathrm{M}$ is the standard error set at 0.05 .

\section{Data collection}

As data on dog breeding and demographics were not available, the surveyed households were identified through a door-to-door approach [21]. In each household, the head of the family or any other family member who gave verbal consent was interviewed. to vaccines and vaccination services [11-14]. A study Before administration of any questionnaire, partici-

Only people aged 18 and older were included in the study. A structured questionnaire was used to collect data through face-to-face interviews. Before the administration of the questionnaire, each participant was briefed on the study background and objectives, and verbal consent was obtained. The obtained data included participant characteristics (gender, age, level of education, religion, knowledge of rabies, and rabies vaccination), household characteristics (area of location, type of housing, pets owned, presence or absence of a dog kennel, main means of transportation, and distance to the veterinary clinic), and dog characteristics (sex, type of breed, purpose of keeping, confinement status, behavior, and vaccination status).

\section{Statistical analysis}

The obtained data were recorded in Microsoft Excel 2016 database for processing and calculating the percentages. The association between explicative variables and the vaccination status of dogs was determined using the Rx64 3.6.1 software (The R Foundation for Statistical Computing, https:// cran.r-project.org/bin/windows/base/old/3.6.1/) to perform Chi-square test and Fisher's exact test with a $95 \%$ confidence level. For these tests, statistical significance was set at 0.05 .

Table-1: Characteristics of pet owners and surveyed households in Ouagadougou, Burkina Faso, 2019.

\begin{tabular}{|c|c|c|}
\hline Variable & $\begin{array}{l}\text { Number of } \\
\text { observed }\end{array}$ & Frequency $(\%)$ \\
\hline \multicolumn{3}{|l|}{$\operatorname{Sex}(n=384)$} \\
\hline Male & 217 & 56.5 \\
\hline Female & 167 & 43.5 \\
\hline \multicolumn{3}{|c|}{ Age (in years) $(n=384)$} \\
\hline $18-35$ & 146 & 38.0 \\
\hline $36-50$ & 173 & 45.0 \\
\hline 51 and older & 65 & 17.0 \\
\hline \multicolumn{3}{|c|}{ Level of education $(n=384)$} \\
\hline Primary & 80 & 20.8 \\
\hline Secondary & 139 & 36.3 \\
\hline University & 78 & 20.3 \\
\hline Illiterate & 87 & 22.6 \\
\hline \multicolumn{3}{|l|}{ Religion $(n=384)$} \\
\hline Christianity & 215 & 55.9 \\
\hline Islam & 142 & 36.9 \\
\hline Animism & 27 & 7.2 \\
\hline \multicolumn{3}{|l|}{ Study area $(n=384)$} \\
\hline Intraurban & 263 & 68.5 \\
\hline Periurban & 121 & 31.5 \\
\hline \multicolumn{3}{|c|}{ Type of housing $(n=384)$} \\
\hline Rented house & 62 & 16.2 \\
\hline $\begin{array}{l}\text { Personal } \\
\text { property }\end{array}$ & 321 & 83.8 \\
\hline \multicolumn{3}{|c|}{ Owned pets in households $(n=384)$} \\
\hline Dog & 285 & 74.2 \\
\hline Cat & 39 & 10.2 \\
\hline Both dog and cat & 60 & 15.6 \\
\hline \multicolumn{3}{|c|}{ Owned dogs vaccination status $(n=424)$} \\
\hline Vaccinated & 245 & 57.8 \\
\hline Unvaccinated & 179 & 42.2 \\
\hline \multicolumn{3}{|c|}{ Dog kennel observed in surveyed households $(n=345)$} \\
\hline Yes & 94 & 27.2 \\
\hline No & 251 & 72.8 \\
\hline
\end{tabular}




\section{Results}

Description of pet owners and their household characteristics

In this study, most of the respondents were male $(56.5 \%)$ and had a secondary education level (36.3\%). The surveyed households were located in both the intraurban and periurban areas. In these households, a total of 523 pets were counted, including 99 cats and 424 dogs. The total number of households owning a dog was 345 (89.8\%). In terms of animal rabies vaccination status, while no cat was vaccinated, $57.8 \%$ of the dogs were reportedly vaccinated. However, the owners had a vaccination certificate for only $36.5 \%$ of the vaccinated dogs. Tables- 1 and 2 show all data

Table-2: Dog-owning households rabies vaccination adoption (owning dog being vaccinated or not) in Ouagadougou, Burkina Faso, 2019

\begin{tabular}{|c|c|c|c|c|}
\hline Variable & $\begin{array}{c}\text { Number } \\
\text { of } \\
\text { observed }\end{array}$ & $\begin{array}{l}\text { Households in which dogs } \\
\text { were not vaccinated }(\%)\end{array}$ & $\begin{array}{l}\text { Households in which dogs } \\
\text { were vaccinated }(\%)\end{array}$ & p-value \\
\hline \multicolumn{5}{|l|}{ Gender of the respondent $(n=345)$} \\
\hline Male & 207 & $97(46.9)$ & $110(53.1)$ & \multirow[t]{2}{*}{0.01} \\
\hline Female & 138 & $85(61.6)$ & $53(38.4)$ & \\
\hline \multicolumn{5}{|c|}{ Age of respondent (in years) $(n=345)$} \\
\hline $18-35$ & 135 & $62(45.9)$ & $73(54.1)$ & \multirow[t]{3}{*}{0.00} \\
\hline $36-50$ & 158 & $81(51.3)$ & $77(48.7)$ & \\
\hline 51 and above & 52 & $39(75.0)$ & $13(25.0)$ & \\
\hline \multicolumn{5}{|l|}{ Level of education $(n=345)$} \\
\hline Primary & 70 & $54(77.1)$ & $16(22.9)$ & \multirow[t]{4}{*}{0.00} \\
\hline Secondary & 129 & $72(55.8)$ & $57(44.2)$ & \\
\hline University & 72 & $21(29.2)$ & $51(70.8)$ & \\
\hline Illiterate & 74 & $35(47.3)$ & $39(52.7)$ & \\
\hline \multicolumn{5}{|l|}{ Religion of the respondent $(n=345)$} \\
\hline Christianity & 196 & $109(55.6)$ & $87(44.4)$ & \multirow[t]{3}{*}{0.30} \\
\hline Islam & 128 & $65(50.8)$ & $63(49.2)$ & \\
\hline Animism & 21 & $8(38.1)$ & $13(61.9)$ & \\
\hline \multicolumn{5}{|l|}{ Study area $(n=345)$} \\
\hline Intraurban & 231 & $86(37.2)$ & $145(62.8)$ & \multirow[t]{2}{*}{0.00} \\
\hline Periurban & 114 & $96(84.2)$ & $18(15.8)$ & \\
\hline \multicolumn{5}{|l|}{ Type of housing $(n=345)$} \\
\hline Rented house & 49 & $29(59.2)$ & $20(40.8)$ & \multirow[t]{2}{*}{0.30} \\
\hline Owned house & 296 & $153(51.7)$ & $143(48.3)$ & \\
\hline \multicolumn{5}{|c|}{ Main mean of transportation used by the household $(n=345)$} \\
\hline Car & 71 & $21(29.6)$ & $50(70.4)$ & \multirow[t]{3}{*}{0.00} \\
\hline Motorbike & 219 & $117(53.4)$ & $102(46.6)$ & \\
\hline Bicycle & 55 & $44(80.0)$ & $11(20.0)$ & \\
\hline \multicolumn{5}{|c|}{ Estimated distance between household and the closest veterinary clinic $(n=345)$} \\
\hline$<5 \mathrm{~km}$ & 297 & $144(48.5)$ & $153(51.5)$ & \multirow[t]{2}{*}{0.00} \\
\hline$\geq 5 \mathrm{~km}$ & 48 & $38(79.2)$ & $10(20.8)$ & \\
\hline \multicolumn{5}{|c|}{ Having attended to a vaccination campaign in lifetime $(n=345)$} \\
\hline Yes & 148 & $57(38.5)$ & $91(61.5)$ & \multirow[t]{2}{*}{0.00} \\
\hline No & 197 & $125(63.5)$ & $72(36.5)$ & \\
\hline \multicolumn{5}{|c|}{ Knowledge of rabies vector animals $(n=345)$} \\
\hline One to three cited $^{1}$ & 265 & $135(50.9)$ & $130(49.1)$ & \multirow[t]{3}{*}{0.03} \\
\hline Four and above cited & 59 & $30(50.8)$ & $29(49.2)$ & \\
\hline None & 21 & $17(81.0)$ & $4(19.0)$ & \\
\hline Knowledge of disease transmissio & modes $(n=$ & 45) & & \\
\hline Two and above cited ${ }^{2}$ & 149 & $81(64.8)$ & $68(35.2)$ & 0.80 \\
\hline One cited & 177 & $93(65.6)$ & $84(34.4)$ & \\
\hline None & 19 & $8(70.4)$ & $11(29.6)$ & \\
\hline Perceived rabies level of severity & oth in huma & and animal $(\mathrm{n}=345)$ & & \\
\hline Fatal & 116 & $88(56.9)$ & $28(43.1)$ & 0.00 \\
\hline Severe & 138 & $22(86.2)$ & $116(13.8)$ & \\
\hline Benign & 91 & $72(55.8)$ & $19(44.2)$ & \\
\hline Minimum required dog age for va & cination in $\mathrm{B}$ & rkina Faso $(n=345)$ & & \\
\hline Correct answer (three months) & 141 & $60(42.6)$ & $81(57.4)$ & 0.00 \\
\hline Uncorrect answer & 204 & $122(59.8)$ & $82(40.2)$ & \\
\hline Annual frequency of dog vaccinat & $n(n=345)$ & & & \\
\hline Correct answer ( 1 time) & 162 & $51(31.5)$ & $111(68.5)$ & 0.00 \\
\hline Uncorrect answer & 183 & $131(71.6)$ & $52(28.4)$ & \\
\hline Perceived cost of dog vaccination & $n=345)$ & & & \\
\hline Affordable & 103 & $45(43.7)$ & $58(56.3)$ & 0.02 \\
\hline Expensive & 242 & $137(56.6)$ & $105(43.4)$ & \\
\hline
\end{tabular}

${ }^{1}$ Vector animals cited or importance were dog, cat, monkey, cattle, pigs, bats, and reptiles, ${ }^{2}$ roots of transmission cited of importance were bite, scratch, and lick 
regarding the surveyed households and characteristics of the respondents.

\section{Dog vaccination practices of households}

Out of the 345 dog-owning households, $47.2 \%$ reported having their dogs vaccinated. Table-3 shows the reasons given by most of the owners $(52.8 \%)$ for not having their dogs vaccinated. Indeed, many owners did not vaccinate their dogs because they could not transport the dogs to the vaccination site (veterinary clinics or fixed sites for mass vaccination campaigns). Most dog owners were male (60\%) and lived in an intraurban area (66.9\%). As shown in Table-2, the vaccination of dogs against rabies in households was significantly more likely to be adopted by men, owners between 18 and 35 years old, owners with a secondary education level, owners who were located in an intraurban area and closer to a veterinary clinic, owners who had a car as the main means of transportation, owners who had attended a vaccination campaign at least once in their lifetime, owners who knew of at least three rabies vector animals and the requirements for the vaccination of dogs (dog of 3 months old and above, one vaccination per year), and owners who perceived the vaccination cost to be affordable $(p<0.05)$. However, no significant association was observed between vaccination adoption by dog owners and their religion or the type of housing (rented or owned) ( $\mathrm{p}>0.05$ ).

\section{Characteristics and vaccination status of owned dogs}

Table-4 presents the characteristics of the surveyed dogs according to their vaccination status. Male dogs were preferred over female dogs in the study area, with a male per female sex ratio of 1:0.8. However, the males were vaccinated less often than the females, that is, $56.5 \%$ versus $59.4 \%$, respectively, but the difference in vaccination coverage between males and females was not significant ( $p>0.05$ ). Out of the 424 dogs belonging to the surveyed households, 369 were local dogs, whereas the vaccinated dogs were significantly more likely to be cross-bred or exotic $(p<0.05)$. Moreover, most dogs were purchased by their owners $(56.4 \%)$ for guarding purposes $(74.3 \%)$, were not confined $(73.3 \%)$, and were considered obedient by their

Table-3: Given reasons why households did not vaccinate their dogs in Ouagadougou, Burkina Faso, 2019.

\begin{tabular}{lc}
\hline Reason & $\begin{array}{c}\text { Number of households } \\
\text { in which dogs were } \\
\text { not vaccinated (\%) }\end{array}$ \\
\hline $\begin{array}{l}\text { Could not transport dog to } \\
\text { vaccination site }\end{array}$ & $56(30.8)$ \\
$\begin{array}{l}\text { Unable to restrain dog for } \\
\text { vaccination }\end{array}$ & $38(20.9)$ \\
$\begin{array}{l}\text { Vaccination too expensive or no } \\
\text { money to pay for }\end{array}$ & $27(14.8)$ \\
Thought that dog was too young \\
$\begin{array}{l}\text { Dog being aggressive } \\
\text { No reason given }\end{array}$ \\
\begin{tabular}{l} 
Total \\
\hline
\end{tabular}
\end{tabular}

owners $(87 \%)$. The vaccinated dogs were significantly more likely to be owned for guarding, purchased, confined day and night, and obedient $(\mathrm{p}<0.05)$.

\section{Discussion}

Dogs are known worldwide to be the main source of human rabies. Moreover, studies reported that if at least $70 \%$ of dogs are vaccinated against rabies in a given area, the disease can be controlled $[18,19]$. Therefore, knowledge of human- and dog-related drivers that may affect dog vaccination coverage is essential for the planning and implementation of successful mass dog vaccination and rabies elimination campaigns $[22,23]$. Considering this, we designed this study to gain insight into the dog vaccination coverage of owned dogs in Ouagadougou, Burkina Faso, as an area known to be rabies endemic [4,5]. The dog male per female sex ratio obtained (1:0.8) was different from that reported (3.02:10) in Cameroon [24] and (1:1.15) in Nigeria [25]. The observed difference reflects the owner's preference for males in the study area, wherein the dogs are generally kept mainly for house guarding. The percentage of confined dogs in this present study was lower than that found in the Philippines [12]. This could be explained by the fact that in terms of local dog husbandry practices, owned dogs are allowed to go out and come home freely to seek food.

In this present study, the observed dog rabies vaccination coverage was lower than that required to sustain rabies eradication in dogs $[19,26]$. The reasons that owners reported for having not vaccinated their dogs were similar to those of other studies [12,14,21,24]. However, some unvaccinated dog owners in Ethiopia were not able to provide reasons probably due to the fact that they consider rabies as insignificant or they are not well aware of the disease [27].

In relation to the owner's gender, men were significantly more likely to vaccinate their dogs. This observation can be explained by the fact that in many households and given local social practices, only men can make the final decision to vaccinate their dogs in Chad [28]. We also found that the number of periurban households in which dogs were reported to be vaccinated was significantly lower. Indeed, periurban areas are characterized by vulnerable life conditions, and poverty is identified as a serious barrier to vaccine accessibility in Peru [21]. Overall, the percentage of households in which dogs were reported to be vaccinated was significantly associated with the respondent's good level of knowledge regarding rabies and dog vaccination. As suggested in many studies, information and community awareness are key steps for a successful and effective mass dog vaccination program $[4,14,29]$.

As found by Davlin et al. [12], our study showed that dog sex was not significantly associated with dog rabies vaccination status. However, fully confined dogs had a significantly higher probability of being 
Table-4: Dog characteristics according to vaccination status of the 424 dogs identified in the survey in Ouagadougou, Burkina Faso, 2019.

\begin{tabular}{|c|c|c|c|c|}
\hline Variable & $\begin{array}{c}\text { Number } \\
\text { of } \\
\text { observed }\end{array}$ & $\begin{array}{c}\text { Number of } \\
\text { unvaccinated dogs (\%) }\end{array}$ & $\begin{array}{c}\text { Number of } \\
\text { vaccinated dogs }(\%)\end{array}$ & p-value \\
\hline \multicolumn{5}{|l|}{$\operatorname{Sex}(n=424)$} \\
\hline Male & 237 & $103(43.5)$ & $134(56.5)$ & \multirow[t]{2}{*}{0.60} \\
\hline Female & 187 & $76(40.6)$ & $111(59.4)$ & \\
\hline \multicolumn{5}{|l|}{ Breed of dog $(n=424)$} \\
\hline Local & 369 & $177(48.0)$ & $192(52.0)$ & \multirow[t]{3}{*}{0.00} \\
\hline Crossbred & 12 & $2(16.7)$ & $10(83.3)$ & \\
\hline Exotic & 43 & $0(0.0)$ & $43(100.0)$ & \\
\hline \multicolumn{5}{|c|}{ The way the dog was acquired by owner (origin) $(n=424)$} \\
\hline Purchased & 239 & $105(43.9)$ & $134(56.1)$ & \multirow[t]{4}{*}{0.00} \\
\hline Gift & 149 & $56(37.6)$ & $93(62.4)$ & \\
\hline Born in household & 7 & $7(100.0)$ & $0(0.0)$ & \\
\hline Found & 29 & $11(37.9)$ & $18(62.1)$ & \\
\hline \multicolumn{5}{|c|}{ Purpose for keeping a dog $(n=424)$} \\
\hline Guarding & 315 & $143(45.4)$ & $172(54.6)$ & \multirow[t]{2}{*}{0.02} \\
\hline Companionship & 109 & $36(33.0)$ & $73(67.0)$ & \\
\hline \multicolumn{5}{|c|}{ Confinement status $(n=424)$} \\
\hline Confined 24 h/24 & 113 & $86(19.3)$ & $27(80.7)$ & \multirow[t]{2}{*}{0.00} \\
\hline Roaming & 311 & $93(41.2)$ & $218(58.8)$ & \\
\hline \multicolumn{5}{|c|}{ Dog perceived behavior $(n=424)$} \\
\hline Obedient & 369 & $144(39.0)$ & $225(61.0)$ & \multirow[t]{2}{*}{0.00} \\
\hline Aggressive & 55 & $35(63.6)$ & $20(36.4)$ & \\
\hline
\end{tabular}

vaccinated [30,31]. Indeed, roaming dogs are not accustomed to contacts with people and could not be easily constrained by their owners to be vaccinated and receive other veterinary care. This was confirmed by our findings which showed a significantly higher percentage of vaccination in dogs that were perceived to be obedient. Like the confinement status and the perceived behavior of the dog, the breed of the dog, the way the dog was acquired, and the purpose of the dog being owned were significantly associated with the percentage of dog vaccination. Similar results were reported by a previous study in Mexico [11].

This present study showed that the most frequent reasons cited by owners of unvaccinated dogs were the inability to restrain their dogs and the difficulty in transporting them to vaccination points, suggesting that combining the door-to-door approach and increasing the number of vaccination points could improve the accessibility to vaccines and the dog vaccination coverage in rabies-endemic countries.

\section{Conclusion}

The fight against animal and human rabies requires ecological, epidemiological, and social evidence for all involved stakeholders and decision-makers. This study showed that although most of the owned dogs were reported to be vaccinated, the percentage of vaccination coverage was lower than that required to eliminate rabies in animals and humans. The vaccination status was significantly associated with most household- and dog-related variables. The data obtained could aid animal health workers to better understand the demographics of owned dogs and to more effectively plan and develop dog rabies vaccination strategies.

\section{Authors' Contributions}

MS, AS, and RBA designed and supervised study implementation. MS, AS, LDD, and AHBC collected and analyzed data. MS wrote the manuscript draft. WO, RBA, and ZT reviewed the manuscript. All authors read and approved the final manuscript.

\section{Acknowledgments}

All authors would like to thank household members who agreed to participate in this survey. We are also grateful to Dr. Joseph Savadogo, Directeur Général des Services Vétérinaires (Chief of Veterinary Office, Ouagadougou, Burkina Faso) for support and technical assistance provided during the study. The authors did not receive any funds for this study.

\section{Competing Interests}

The authors declare that they have no competing interests.

\section{Publisher's Note}

Veterinary World remains neutral with regard to jurisdictional claims in published institutional affiliation.

\section{References}

1. Savadogo, M., Boushab, M.B., Sondo, K.A., Dabilgou, A. and Kaboré, J. (2016) Children cephalic rabies: About two cases. Rev. Mali Infect. Microbiol., Tome 7: 57-59. Available online: https://revues.ml/index.php/remim/issue/ view/115 (Retrieved on 15-04-2021). This article was originally published in French.

2. Savadogo, M., Kyelem, N., Boushab, M.B., Sondo, K.A., Thiombiano, R., Simpore, L. and Ouedraogo, A. (2017) Furious rabies transmitted by a roaming dog. Méd. Afr. Noire, 64(4): 243-246. Available online: http://www.santetropicale. $\mathrm{com} / \mathrm{manelec} / \mathrm{fr} /$ recherche.asp (Retrieved on 15-04-2021). 
This article was originally published in French.

3. Ouermi, A.S., Dravé, A., Sawadogo, N., Barro, M., Sanogo, B. and Savadogo, H. (2018) Rabies in children: Diagnostic difficulties in an epileptic adolescent at the Regional University Hospital of Ouahigouya, Burkina Faso. Health Sci. Dis., 19(2): 141-144. Available online: http://www.hsd-fmsb.org/ index.php/hsd/article/view/1036 (Retrieved on 15-04-2021). This article was originally published in French.

4. Savadogo, M., Koné, P., Dahourou, L.D., Manishimwe, R., Sow, A., Nébié, L., Antoine-Moussiaux, N. and BadaAlambedji, R. (2020) Rabies epidemiology and community knowledge, attitudes and practices in Burkina Faso. Rev. Elev. Med. Vet. Pays Trop., 73(2): 133-144.

5. Sondo, K.A., Okenga, Y.C., Diop, S.A., Kaboré, B.E., Diallo, I., Kyelem, N., Basshono, J., Thombiano, R. and Kam, L. (2015) Rabies in children: Report of 24 cases at the Yalgado Ouedraogo University Hospital Center of Ouagadougou in Burkina Faso. J. Trop. Dis., 3(3): 168.

6. Dodet, B., Adjogoua, E.V., Aguemon, A.R., Amadou, O.H., Atipo, A.L., Baba, B.A., Bara Ada, S., Boumandouki, P., Bourhy, H., Diallo, M.K., Diarra, L., Diop, B.M., Diop, S.A., Fesriry, B., Gosseye, S., Hassar, M., Kingé, T., Nzamba, T.E., Yandoko, E., Nzengué, E., Ramahefalalao, E.F., Ratsitorahina, M., Simpore, L., Soufi, A., Tejiokem, M., Thiombano, R., Tiembré, I., Traoré, A.K. and Wateba, M.I. (2008) Fighting rabies in Africa: The Africa Rabies expert bureau. Vaccine, 26(50): 6295-6298.

7. Tiembré, I., Aka-Kone, D.M.B., Konan, Y.E., Vroh, J.B.B., Ekra, K.D., Dagnan, N.S., Aka, J., Tagliante-Saracino, J. and Odehouri-Koudou, P. (2009) Compliance with rabies vaccination treatment in subjects exposed to rabies in Abidjan (Côte d'Ivoire). Santé Publique, 21(6): 595-603. This article was originally published in French.

8. Diop, S.A., Manga, N.M., Dia, N.M., Ndour, C.T., Seydi, M., Soumare, M., Diop, B.M. and Sow, P.S. (2007) Update on human rabies in Senegal from 1986 to 2005. Méd. Mal. Infect., 37(12): 787-791. This article was originally published in French.

9. Dao, S., Abdillahi, A.M., Bougoudogo, F., Touré, K. and Simbé, C. (2006) Epidemiological aspects of human and animal rabies in the urban area of Bamako, Mali. Bull. Soc. Pathol. Exot., 99(3): 183-186. This article was originally published in French.

10. Burkina Faso. (2009) Annuaire Statistique. Ministère de la Santé, Direction Générale de L'information et des Statistiques Sanitaires, Ouagadougou, Burkina Faso.

11. Flores-Ibarra, M. and Estrella-Valenzuela, G. (2004) Canine ecology and socioeconomic factors associated with dogs unvaccinated against rabies in a Mexican city accross the US-Mexico border. Prev. Vet. Med., 62(2): 79-87.

12. Davlin, S., Lapiz, S.M., Miranda, M.E. and Murray, K. (2013) Factors associated with dog rabies vaccination in Bohol, Philippines: Results of a cross-sectional cluster survey conducted following the Island-Wide Rabies Elimination Campaign. Zoonoses Public Health, 60(7): 494-503.

13. Savadogo, M. and Boushan, M.B. (2015) Rabies in children: A risk still unknown to exposed populations. Med. Sante Trop., 25(2): 222-224. This article was originally published in French.

14. Mosimann, L., Traoré, A., Mauti, S., Léchenne, M., Obrist, B., Véron, R., Hattendorf, J. and Zinsstag, J. (2017) Mixed methods approach to assess animal vaccination programmes: The case of rabies control in Bamako, Mali. Acta Trop., 165: 203-215.

15. Beran, G.W. (1991) Urban rabies. In: The Natural History of Rabies. $2^{\text {nd }}$ ed. CRC Press, Boca Raton, FL. p427-443.
16. Coleman, P.G. and Dye, C. (1996) Immunization coverage required to prevent outbreaks of dog rabies. Vaccine, 14(3): 185-186.

17. Hampson, K., Dushoff, J., Cleaveland, S., Haydon, D.T., Kaare, M., Packer, C. and Dobson, A. (2009) Transmission dynamics and prospects for the elimination of canine rabies. PLoS Biol., 7(3): e53.

18. Lembo, T., Hampson, K., Kaare, M.T., Knobel, D., Kazwala, R.R. and Haydon, D.T. (2010) The feasibility of canine rabies elimination in Africa: Dispelling doubts with data. PLoS Negl. Trop. Dis., 4(2): e626.

19. Zinsstag, J., Lechenne, M., Laager, M., Mindekem, R., Naïssengar, S., Oussiguéré, A., Bidjeh, K., Rives, G., Tessier, J., Madjaninan, S., Ouagal, M., Moto, D.D., Alfaroukh, I.O., Muthiani, Y., Traoré, A., Hattendorf, J., Lepelletier, A., Kergoat, L., Bourhy, H., Dacheux, L., Stadler, T. and Chitnis, N. (2017) Vaccination of dogs in an African city interrupts rabies transmission and reduces human exposure. Sci. Transl. Med., 9(42): eaaf6984.

20. Burkina Faso, Ministère de l'Urbanisme et de l'Habitat. (2017) Etat des Villes au Burkina Faso de 1995 à 2015. Perspective-Agricole, Ouagadougou. p233.

21. Castillo-Neyra, R., Brown, J., Borrini, K., Arevalo, C., Levy, M.Z., Buttenheim, A., Hunter, G.C., Becerra, V., Behrman, J. and Paz-Soldan, V.A. (2017) Barriers to dog rabies vaccination during an urban rabies outbreak: Qualitative findings from Arequipa, Peru. PLoS Negl. Trop. Dis., 11(3): e0005460.

22. World Health Organization. (1992) Expert Committee on Rabies: Eighth Report. World Health Organization, Geneva, Switzerland.

23. Cleaveland, S., Kaare, M., Knobel, D. and Laurenson, M.K. (2006) Canine vaccination providing broader benefits for disease control. Vet. Microbial., 117(1): 43-50.

24. Bouli, F.P.N., Awah-Ndukum, J., Mingoas, K.J.P., Tejiokem, M.C. and Tchoumboue, J. (2020) Dog demographics and husbandry practices related with rabies in Cameroon. Trop. Anim. Health Prod., 52(3): 979-987.

25. Hamadou, S.E., Dzikwi, A.A., Kwaga, J., Kazeem, H.M., Umoh, J.U. and Hambolu, D.A. (2014) Dog ecology and population in Lagos state, Nigeria. Glob. J. Health Sci., 6(2): 209-220

26. Perry, B.D. (1993) Dog ecology in Eastern and Southern Africa: Implications for rabies control. Onderstepoort $J$. Vet. Res., 60(4): 429-436. Available online: http://www.hdl. handle.net/2263/41177 (Retrieved on 15-04-2021).

27. Ali, A., Eshetu, Y.A. and Sifer, D. (2013) A study on knowledge, attitude and practice of rabies among residents in Addis ababa, Ethiopia, Ethiop. Vet. J., 17(12): 19-35.

28. Mindekem, R., Lechenne, M., Alfaroukh, I.O., Moto, D.D., Zinsstag, J., Ouedraogo, T.L. and Salifou, S. (2017) Evaluation of Knowledge-Attitudes-Practices of the populations in the health districts of Benoye, Laoukassy, Moundou and South N'Djamena towards canine rabies in Chad. Pan. Afr. Med. J., 27: 24. This article was originally published in French.

29. Sambo, M., Lembo, T., Cleaveland, S., Ferguson, H.M., Sikana, L., Simon, C., Urassa, H. and Hampson, K. (2014) Knowledge, attitudes and practices (KAP) about rabies prevention and control: A community survey in Tanzania. PLoS Negl. Trop. Dis., 8(12): e3310.

30. Awoyomi, O.J., Adeyemi, I.G. and Awoyomi, F.S.O. (2007) Socioeconomic factors associated with non-vaccination of dogs against rabies in Ibadan, Nigeria. Niger. Vet. J., 28(3): 59-63.

31. Beran, W.B. and Frith, M. (1988) Domestic animal rabies control: An overview. Rev. Infect. Dis., 10(4): S672-S677.

\section{$* * * * * * * *$}

